\title{
Glucose Intolerance in Patients With Cystic Fibrosis: Sex-Based Differences in Clinical Score, Pulmonary Function, Radiograph Score, and 6-Minute Walk Test
}

\author{
Bruna Ziegler CPT MSc, Claudine Lacerda Oliveira CCN, Paula Maria Eidt Rovedder CPT MSc, \\ Sandra Jungblut Schuh MD, Fernando Antônio Abreu e Silva MD PhD, and \\ Paulo de Tarso Roth Dalcin MD PhD
}

\begin{abstract}
OBJECTIVE: To determine the sex-specific relationships between glucose intolerance and Shwachman-Kulczycki clinical score, lung function, Brasfield chest-radiograph score, and exercise capacity in patients with cystic fibrosis (CF). METHODS: We used a cross-sectional study design and included $\mathbf{C F}$ patients $\geq \mathbf{1 0}$ years old. All patients had clinical and nutritional evaluation, oral glucose tolerance test, spirometry, chest radiograph, and 6-min walk test (6MWT). Patients were classified as having normal glucose tolerance, impaired glucose tolerance, or CF-related diabetes mellitus. RESULTS: We included 88 patients: 59 with normal glucose tolerance, 15 with impaired glucose tolerance, and 14 with CF-related diabetes. Shwachman-Kulczycki clinical score $(P=.04)$, at-rest $S_{\mathrm{pO}_{2}}$ $(P=.001), \mathrm{S}_{\mathrm{pO}_{2}}$ difference before versus after 6MWT $(P=.001)$, and Brasfield chest-radiograph score $(P=.01)$ were significantly lower in the impaired-glucose-tolerance group than in the normal-glucosetolerance group, but did not differ from the CF-related-diabetes group. In female patients only, percentof-predicted $\mathrm{FEV}_{1}$ was significantly lower in the impaired-glucose-tolerance group than in the normalglucose-tolerance group $(P=.02)$, but did not differ from the $\mathrm{CF}$-related-diabetes group $(P=.10)$. There was a significant relationship between glucose intolerance and sex when clinical score, 6-min walk distance, $\mathrm{FEV}_{1}$, and radiograph score were combined in a multivariate analysis. CONCLUSIONS: In patients with $\mathrm{CF}$, glucose intolerance was associated with poor clinical score, lower at-rest $\mathrm{S}_{\mathbf{p O}_{2}}$, greater $\mathrm{S}_{\mathrm{pO}_{2}}$ difference before versus after 6MWT, poor lung function, and lower radiograph score. Overall, multivariate analysis indicated poorer performance in the latter variables in female patients with glucose intolerance than in male patients with glucose intolerance. Key words: cystic fibrosis; glucose intolerance; Shwachman-Kulczycki score; lung function; 6-minute walk test; Brasfield chest radiograph score; oral glucose tolerance test. [Respir Care 2011;56(3):290-297. (C) 2011 Daedalus Enterprises]
\end{abstract}

Bruna Ziegler CPT MSc is affiliated with Serviço de Pneumologia, Hospital de Clínicas de Porto Alegre, Universidade Federal do Rio Grande do Sul, Porto Alegre, Brazil. Claudine Lacerda Oliveira CCN is affiliated with Serviço de Nutrição, Hospital de Clínicas de Porto Alegre, Porto Alegre, Brazil. Paula Maria Eidt Rovedder CPT MSc is affiliated with Universidade Federal do Rio Grande do Sul, and with Faculdade de Fisioterapia, Centro Universitário Metodista, Instituto Porto Alegre da Igreja Metodista, Porto Alegre, Brazil. Sandra Jungblut Schuh MD is affiliated with Serviço de Radiologia, Hospital de Clínicas de Porto Alegre, Porto Alegre, Brazil. Fernando Antônio Abreu e Silva MD PhD is affiliated with Faculdade de Medicina, Universidade Federal do Rio Grande do Sul, and with Serviço de Pediatria, Hospital de Clínicas de Porto Alegre, Porto Alegre, Brazil. Paulo de Tarso Roth Dalcin MD PhD is

\begin{abstract}
affiliated with Faculdade de Medicina, Universidade Federal do Rio Grande do Sul, and with Serviço de Pneumologia, Hospital de Clínicas de Porto Alegre, Porto Alegre, Brazil.
\end{abstract}

The authors have disclosed no conflicts of interest.

Correspondence: Bruna Ziegler CPT MSc, Serviço de Pneumologia, Hospital de Clínicas de Porto Alegre, Travessa Miranda e Castro 70/204, Bairro Santana, Porto Alegre, Rio Grande do Sul, 90040-280 Brazil. E-mail: brunaziegler@yahoo.com.br.

DOI: $10.4187 /$ respcare. 00726 


\section{Glucose Intolerance in Patients With Cystic Fibrosis}

\section{Introduction}

Abnormal glucose tolerance is a frequent comorbidity in cystic fibrosis (CF) patients, and is associated with a poor prognosis. ${ }^{1} \mathrm{CF}$ patients with impaired glucose tolerance have reduced pancreatic $\beta$ cell number and a loss of insulin secretion. ${ }^{2}$ The prevalence of glucose intolerance in $\mathrm{CF}$ patients has risen in recent decades, owing to increased longevity; older individuals are more likely to have glucose intolerance. ${ }^{3} \mathrm{CF}$-related diabetes is associated with greater morbidity and mortality. ${ }^{4}$ Several studies have reported a decline in nutritional and pulmonary status 2-4 years before the diagnosis of CF-related diabetes. ${ }^{5,6}$

The decrease in exercise tolerance in CF is associated with deterioration of lung function and nutritional status, and with shorter survival. ${ }^{7-9}$ The 6-min walk test (6MWT) is a submaximal exercise test used in patients with cardiac and pulmonary disease, and reflects quality of life and the ability to perform day-to-day activities. ${ }^{10}$ However, the impact of glucose intolerance on exercise capacity has not been determined. 1,3,6,11-15

Female CF patients have worse lung function, earlier acquisition of chronic mucoid Pseudomonas aeruginosa, ${ }^{16}$ and worse survival ${ }^{17}$ than male CF patients. Sex is also known to influence pulmonary function in patients with CF-related diabetes. ${ }^{16,18}$ Female subjects with CF-related diabetes have a remarkably poorer prognosis than all male $\mathrm{CF}$ patients, and female patients with $\mathrm{CF}$ but without diabetes. ${ }^{19}$ The cause of the sex differences in $\mathrm{CF}$ prognosis is not clear; it might involve the interaction of female hormones and diabetes to promote a pro-inflammatory state, or androgens might protect male subjects from the catabolic effects of insulin deficiency. Alternatively, the appearance of frank diabetes in female subjects with CF may simply be a marker for another biological difference that is not yet known. ${ }^{20}$

We investigated sex-specific relationships between glucose intolerance and Shwachman-Kulczycki clinical score, lung function, Brasfield chest-radiograph score, and exercise capacity in CF patients.

\section{Methods}

\section{Study Design}

We conducted a cross-sectional study. All CF patients who volunteered were sequentially included. In each patient, during the same week, we performed nutritional evaluation, oral glucose tolerance test, pulmonary function tests, chest radiograph, and 6MWT. The study was approved by the Hospital de Clínicas de Porto Alegre ethics committee, and we obtained informed consent from each patient.

\section{Population}

We recruited patients $\geq 10$ years old from the pediatric and adult CF program at Hospital de Clínicas de Porto Alegre. The CF diagnosis was according to consensus criteria. ${ }^{21}$ All patients were clinically stable, defined as no medication changes in the last 30 days, and at least 30 days since completing the most recent course of intravenous or oral antibiotics for pulmonary exacerbation. We excluded patients who refused to participate; were pregnant; had a cardiac, orthopedic, or traumatological condition; or who could not endure the diagnostic tests.

\section{Measurements and Procedures}

The Shwachman-Kulczycki clinical score was determined by the physician of the CF team. The ShwachmanKulczycki scoring system ${ }^{22}$ is a general score of clinical severity, with 4 domains: general activity, physical examination, nutrition, and chest radiograph findings. Each domain is scored out of 25 points, and the domain scores are added to give the total score (out of 100). A higher score reflects a better clinical status.

Nutritional status was assessed as body mass index (BMI) in patients $\geq 18$ years old, or BMI percentile in patients $<18$ years old. ${ }^{23,24}$ Patients were classified according to their nutritional status into 3 groups: normal nutrition $\left(\mathrm{BMI} \geq 20 \mathrm{~kg} / \mathrm{m}^{2}\right.$ or BMI percentile $>25$ th percentile), nutritional risk (BMI $18.5-20.0 \mathrm{~kg} / \mathrm{m}^{2}$ or BMI percentile 10th-25th percentile), or nutritional depletion $\left(\mathrm{BMI}<18.5 \mathrm{~kg} / \mathrm{m}^{2}\right.$ or BMI percentile $<10$ th percentile). ${ }^{23,24}$

We also reviewed the bacteria cultured from at least 2 routine sputum samples over at least 12 months. We identified Staphylococcus aureus, Pseudomonas aeruginosa, and Burkholderia cepacia.

The pulmonary function tests (MasterScreen, v 4.31, Jaeger, Würzburg, Germany) included forced vital capacity (FVC) and $\mathrm{FEV}_{1}$, each measured 3 times, and the best effort was recorded. All the data are expressed as percentof-predicted response for age, height, and sex. ${ }^{25}$

The chest radiographs were scored with the Brasfield scoring system ${ }^{26}$ by a board-certified radiologist who was blinded to the patients' clinical status.

All patients underwent a 2-hour oral glucose tolerance test except those who had a previous diagnosis of fasting CF-related diabetes. Per the American Diabetes Association guidelines, the oral glucose tolerance test involved an overnight fast, then ingestion of a glucose solution (1.75 g glucose $/ \mathrm{kg}$ of body weight, but a maximum of $75 \mathrm{~g}$ glucose) in less than 5 min. ${ }^{27}$ Blood samples were taken at zero minutes and 120 min to measure the plasma glucose concentration. We classified the patients according to glucose tolerance: normal (plasma glucose $<140 \mathrm{mg} / \mathrm{dL}$ at 


\section{Glucose Intolerance in Patients With Cystic Fibrosis}

2 hours), impaired (glucose $140-200 \mathrm{mg} / \mathrm{dL}$ at 2 hours), and CF-related diabetes (glucose $>200 \mathrm{mg} / \mathrm{dL}$ at 2 hours, or 2 fasting plasma glucose $>126 \mathrm{mg} / \mathrm{dL}$ ).

We performed 6MWT according to the American Thoracic Society guidelines. ${ }^{10}$ We recorded 6-min walk distance and $\mathrm{S}_{\mathrm{pO}_{2}}$ (NPB-40, Nellcor Puritan Bennett, Pleasanton, California) before and after 6MWT. We also express the walk distance in percent-of-predicted values. ${ }^{28,29}$

\section{Statistical Analysis}

Data are expressed as number of cases (proportions), mean $\pm \mathrm{SD}$, or median and interquartile range. Categorical comparisons were via chi-square test with adjusted standardized residuals. We used one-way analysis of variance or Kruskal-Wallis test to compare continuous variables. We used the Tukey test or the Kruskal-Wallis $\mathrm{Z}$ test for post-hoc tests.

We used the general linear model multivariate procedure to conduct a multivariate analysis of variance (MANOVA) to analyze dependent variables (ShwachmanKulczycki clinical score, 6-min walk distance, lung function, and Brasfield chest-radiograph score). We used sex and glucose tolerance, and the interaction between the two, as the independent variables in each model. We used the Tukey test post-hoc for multiple comparisons among the glucose-tolerance and sex groups. We used the Pillai trace statistic to determine the significance of the overall MANOVA results. MANOVA is a special case of a general linear model. One reason for choosing MANOVA over multiple univariate analysis of variance is that MANOVA more appropriately reflects the multivariate reality that the research is trying to model. In the MANOVA design, the groups (sex and glucose tolerance) are measured on several dependent variables. MANOVA takes advantage of this by combining the dependent variables in a way that makes the differences among the groups as large as possible. ${ }^{30} \mathrm{We}$ also reported a MANOVA for analysis of the same dependent and independent variables, but with age as the covariate.

We used estimated marginal means to present the mean response for each factor, adjusted for any other variables in the model.

We determined correlation coefficients via Pearson linear correlation or the Spearman rank correlation. Data analysis was with statistics software (SPSS 15.0, SPSS, Chicago, Illinois, and NCSS 2000, NCSS, Kaysville, Utah). Differences were considered statistically significant when $P<.05)$. We report 2-tailed probabilities.

\section{Results}

We screened 107 CF patients, between March 2007 and August 2008. Ten patients refused to participate, and 9 were excluded because they failed to complete all required examinations, so 88 patients completed the required protocol. The excluded patients did not significantly differ from the included patients with respect to age $(P=.35)$, sex $(P=.17)$, race $(P=.89)$, BMI $(P=.83)$, pancreatic insufficiency $(P=.72)$, glucose tolerance $(P=.57)$, FVC $(P=.54)$, or $\mathrm{FEV}_{1}(P=.54)$.

The study included 43 female and 45 male patients. Their mean \pm SD age was $20 \pm 7$ y (range $10-49$ y). There were 84 white patients and 4 non-white patients. Their mean \pm SD BMI was $20 \pm 2 \mathrm{~kg} / \mathrm{m}^{2}$. Their mean \pm SD FVC was $75 \pm 24 \%$ of predicted, and their mean FEV $_{1}$ was $65 \pm 28 \%$ of predicted. There was no significant difference in age between the males and females $(P=.11)$ or between the glucose-tolerance groups $(P=.46)$. Only one patient was treated with oral steroids during the study period.

Table 1 describes the subjects and subgroups. There were 59 patients $(67 \%)$ with normal glucose tolerance, 15 (17\%) with impaired glucose tolerance, and 14 (16\%) with CF-related diabetes ( 7 with fasting hyperglycemia, and 7 with hyperglycemia 2 hours after oral glucose tolerance test). The patients with CF-related diabetes had the CF diagnosis significantly earlier in life than those in the normal-glucose-tolerance group and the impaired-glucosetolerance group $(P=.007)$. Seventeen patients had pancreatic insufficiency: 16 of them were in the normalglucose-tolerance group, and the other was in the impairedglucose-tolerance group $(P=.03)$. Methicillin-resistant $S$. aureus was significantly more common in the CF-related-diabetes group than in the normal-glucose-tolerance group or the impaired-glucose-tolerance group $(P=.04)$. There was no difference between the groups in $P$. aeruginosa colonization $(P=.24)$.

There were no significant differences between the male and female groups in at-rest $\mathrm{S}_{\mathrm{pO}_{2}}(P=.48)$ or $\mathrm{S}_{\mathrm{pO}_{2}}$ before versus after $6 \mathrm{MWT}(P=.96)$. The at-rest $\mathrm{S}_{\mathrm{pO}_{2}}$ was slightly lower in the impaired-glucose-tolerance group (96 $\pm 2 \%)$ and the CF-related-diabetes group $(96 \pm 2 \%)$ than in the normal-glucose-tolerance group $(98 \pm 2 \%)(P=.001)$. $\mathrm{S}_{\mathrm{pO}_{2}}$ after $6 \mathrm{MWT}$ and $\mathrm{S}_{\mathrm{pO}_{2}}$ difference before versus after $6 \mathrm{MWT}$ were significantly lower in the impaired-glucosetolerance group (90 $\pm 10 \%$ and $6 \pm 9 \%$, respectively) than in the normal-glucose-tolerance group (97 $\pm 4 \%$ and $1 \pm 3 \%$, respectively) $(P=.001)$, but did not differ from the CF-related-diabetes group $(94 \pm 6 \%$ and $2 \pm 4 \%$, respectively) $(P=.30)$.

In the MANOVA tests of between-subject effects, there were no significant differences for sex with respect to Shwachman-Kulczycki clinical score, $\mathrm{FEV}_{1}$, or Brasfield chest-radiograph score $(P=.83, .47$, and .96 , respectively). The 6-min walk distance was significantly lower in the female patients than the male patients $(563 \pm 88 \mathrm{~m}$ vs 


\section{Glucose Intolerance in Patients With Cystic Fibrosis}

Table 1. Subjects

\begin{tabular}{|c|c|c|c|c|c|}
\hline & $\begin{array}{c}\text { Total } \\
(n=88)\end{array}$ & $\begin{array}{l}\text { Normal Glucose } \\
\text { Tolerance } \\
(n=59)\end{array}$ & $\begin{array}{c}\text { Impaired Glucose } \\
\text { Tolerance } \\
(n=15)\end{array}$ & $\begin{array}{l}\text { CF-Related } \\
\text { Diabetes } \\
(n=14)\end{array}$ & $P$ \\
\hline \multicolumn{6}{|l|}{ Age $-y$} \\
\hline Whole cohort & $20 \pm 7$ & $19 \pm 8$ & $22 \pm 7$ & $20 \pm 5$ & .40 \\
\hline Male & $19 \pm 6$ & $18 \pm 7$ & $19 \pm 5$ & $21 \pm 5$ & .50 \\
\hline Female & $21 \pm 8$ & $21 \pm 8$ & $25 \pm 8$ & $17 \pm 6$ & .28 \\
\hline Age at $\mathrm{CF}$ diagnosis—median (IQR), y & $3(0-11)$ & $5(1-11)^{*}$ & $5(1-20)^{*}$ & $0(0-2) \dagger$ & .007 \\
\hline Male/female—no. & $45 / 43$ & $27 / 32$ & $7 / 8$ & $11 / 3$ & .08 \\
\hline Meconium ileus-no. (\%) & $7(8)$ & $4(57)$ & $0(0)$ & $3(43)$ & .09 \\
\hline $\mathrm{BMI}-\mathrm{kg} / \mathrm{m}^{2}$ & $20 \pm 2$ & $20 \pm 3$ & $20 \pm 2$ & $19 \pm 2$ & .48 \\
\hline \multicolumn{6}{|l|}{ Nutritional classification-no. (\%) } \\
\hline Normal nutrition & $36(67)$ & $23(66)$ & $8(80)$ & $5(56)$ & .27 \\
\hline Nutritional risk & $11(20)$ & $8(23)$ & $2(20)$ & $1(11)$ & \\
\hline Nutritional depletion & $7(13)$ & $4(11)$ & $0(0)$ & $3(33)$ & \\
\hline Pancreatic insufficiency-no. (\%) & $17(19)$ & $16(27) \ddagger$ & $1(7)$ & $0(0) \ddagger$ & .03 \\
\hline \multicolumn{6}{|l|}{ Bacterial colonization-no. (\%) } \\
\hline MRSA & $17(19)$ & $8(13) \div$ & $3(20)$ & $6(43) \ddagger$ & .04 \\
\hline MSSA & $60(68)$ & $48(81) \ddagger$ & $5(33) \ddagger$ & $7(50)$ & $<.001$ \\
\hline Pseudomonas aeruginosa & $61(69)$ & $38(64)$ & $13(87)$ & $10(71)$ & .24 \\
\hline Burkholderia cepacia & $16(18)$ & $8(14)$ & $4(27)$ & $4(29)$ & .27 \\
\hline $\begin{array}{l}\text { Plus-minus values are mean } \pm \text { SD. } \\
* \text { Via } 1 \text {-way analysis of variance with the post-hoc Tu } \\
\dagger \text { Significantly different mean or median. } \\
\text { ‡Chi-square test for categorical variables; standard ad } \\
\text { CF = cystic fibrosis } \\
\text { IQR = interquartile range } \\
\text { BMI = body mass index } \\
\text { MRSA = methicillin-resistant Staphylococcus aureus } \\
\text { MSSA = methicillin-sensitive Staphylococcus aureus }\end{array}$ & $\begin{array}{l}\text { Kruskal-Wal } \\
\text { idual }>1.96 \mathrm{o}\end{array}$ & $\begin{array}{l}\text { st-hoc } \mathrm{Z} \text { test for continu } \\
\text { (implies percentages sig }\end{array}$ & $\begin{array}{l}\text { les } \\
\text { different). }\end{array}$ & & \\
\hline
\end{tabular}

$606 \pm 78 \mathrm{~m}$, respectively) $(P=.009)$. There were no significant differences in 6-min walk distance or $\mathrm{FEV}_{1}$ between the glucose-tolerance groups $(P=.28$ and .25 , respectively).

In a post-hoc test, the Shwachman-Kulczycki clinical score was significantly lower in the impaired-glucose-tolerance group ( $69 \pm 13$ points) and the CF-related-diabetes group $(67 \pm 15$ points $)$ than in the normal-glucose-tolerance group (79 \pm 13 points $)(P=.04$ and .03 , respectively). Brasfield chest-radiograph score was significantly lower in the impaired-glucose-tolerance group $(13.7 \pm 5.3$ points) and the CF-related-diabetes group (14.3 \pm 4.8 points) than in the normal-glucose-tolerance group (18.0 \pm 4.8 points $)(P=.01$ and .04 , respectively $)$.

There were significant differences in the interaction between sex and glucose-tolerance group with respect to $\mathrm{FEV}_{1}(P=.03)$. In the female patients, $\mathrm{FEV}_{1}$ was significantly lower in the impaired-glucose-tolerance group $(43 \pm 23 \%)$ than in the normal-glucose-tolerance group $(73 \pm 29 \%)(P=.02)$, but did not differ from the CFrelated-diabetes group $(88 \pm 11 \%)(P=.10)$. In the male patients, $\mathrm{FEV}_{1}$ did not differ significantly between the normal-glucose-tolerance group $(66 \pm 26 \%)$, the impaired- glucose-tolerance group $(69 \pm 28 \%)$ or the CF-relateddiabetes group $(51 \pm 29 \%)(P=.23)$.

The percent-of-predicted 6-min walk distances were significantly lower in the female patients $(74 \pm 12 \%)$ than in the male patients $(80 \pm 11 \%)(P=.002)$. There were no significant differences in percent-of-predicted 6-min walk distance between the glucose-tolerance groups $(P=.08)$. There were also no significant differences in the interaction between sex and glucose-tolerance group $(P=.31)$.

Figure 1 shows the sex-specific analysis by glucosetolerance group, Shwachman-Kulczycki score, $\mathrm{FEV}_{1}$, 6-min walk distance, and Brasfield radiograph score. Table 2 summarizes the multivariate analysis for Shwachman-Kulczycki clinical score, 6-min walk distance, $\mathrm{FEV}_{1}$, and Brasfield chest-radiograph score, according to glucose-tolerance group. There was no significant effect for sex $(P=.05)$ or glucose-tolerance group $(P=.08)$. There was a significant effect for interaction between sex and glucose-tolerance group $(P=.02)$. Results were similar via MANOVA with age as the covariate.

Figure 2 shows the plasma glucose 2 hours after glucose ingestion relative to Shwachman-Kulczycki score, $\mathrm{FEV}_{1}$, 6-min walk distance and Brasfield radiograph score. 


\section{Glucose Intolerance in Patients With Cystic Fibrosis}
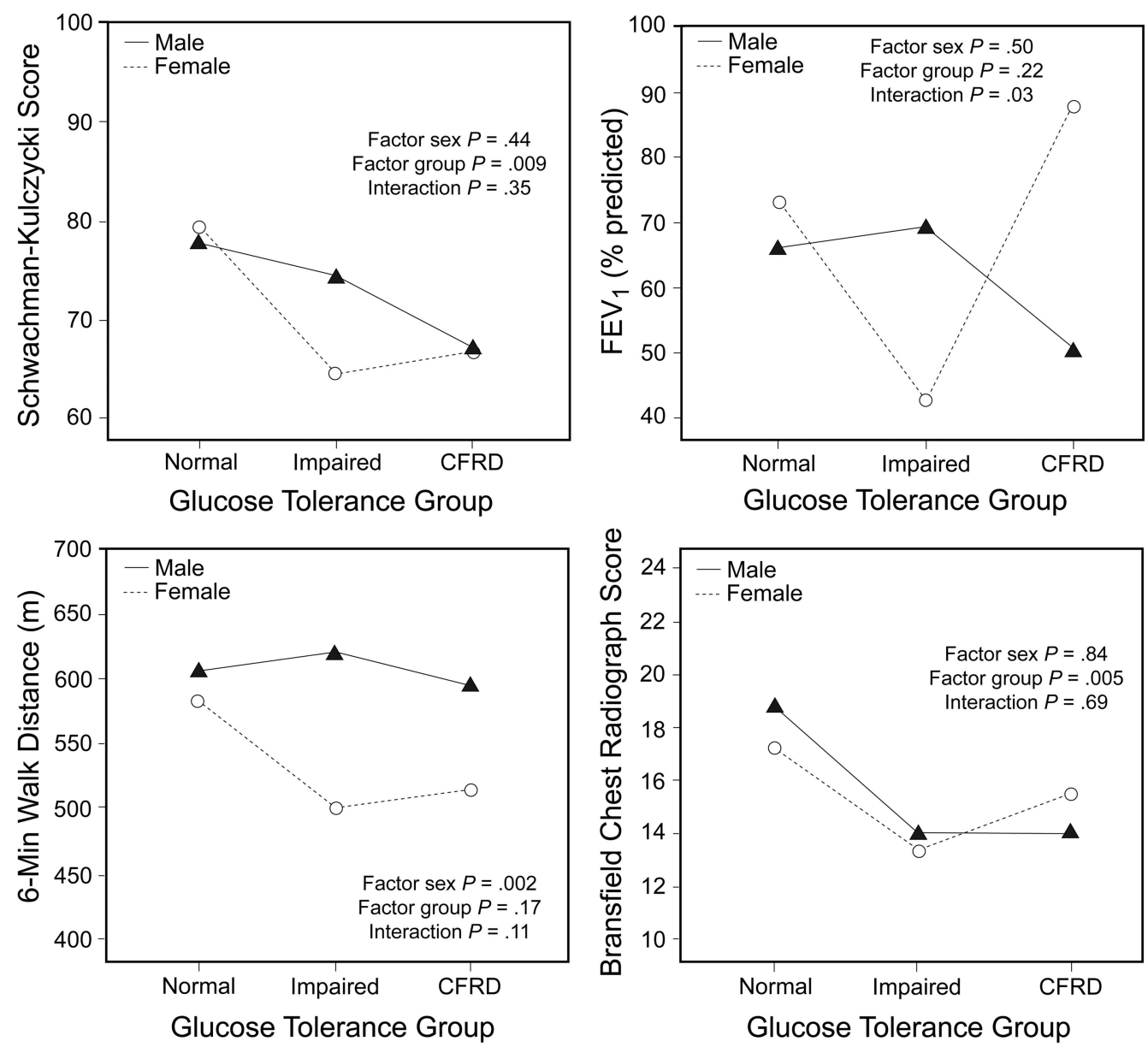

Fig. 1. General linear model analysis for the male and female groups, and the glucose-tolerance groups versus Schwachman-Kulczycki clinical score, $\mathrm{FEV}_{1}, 6$-min walk distance, and Brasfield chest radiograph score. CFRD $=$ cystic-fibrosis-related diabetes.

\section{Discussion}

Our main finding is that glucose intolerance in CF patients is related to lower Brasfield chest-radiograph score, lower at-rest $\mathrm{S}_{\mathrm{pO}_{2}}$, greater $\mathrm{S}_{\mathrm{pO}_{2}}$ difference before versus after 6MWT, and poorer lung function. Also, there was a

Table 2. Multivariate Analysis of Clinical Score, 6-Minute Walk Distance, $\mathrm{FEV}_{1}$, and Chest Radiograph Score*

\begin{tabular}{|c|c|c|c|c|}
\hline Fixed Factor & $\begin{array}{c}\text { Pillai } \\
\text { Value } \dagger\end{array}$ & $\mathrm{F}$ & $P$ & $\begin{array}{c}\text { Partial Eta } \\
\text { Squared } \ddagger\end{array}$ \\
\hline Sex & 0.11 & 2.47 & .05 & 0.11 \\
\hline Glucose-tolerance group & 0.17 & 1.83 & .08 & 0.09 \\
\hline Sex and glucose-tolerance group & 0.21 & 2.29 & .02 & 0.11 \\
\hline \multicolumn{5}{|c|}{$\begin{array}{l}\text { * Multivariate analysis of variance with sex and glucose-tolerance group as fixed factc } \\
\text { The Pillai trace statistic was used for multivariate analysis of variance. } \\
\dagger \text { The Pillai trace positive-valued statistic: the higher the value, the more the factor } \\
\text { contributed to the model. } \\
\ddagger \text { Partial eta squared overestimates the actual effect size in an F test; it describes the } \\
\text { proportion of total variability attributable to a factor. }\end{array}$} \\
\hline
\end{tabular}

significant interaction between glucose intolerance and sex in regards to lung function. When the 4 non-collinear dependent variables (clinical score, 6-min walk distance, $\mathrm{FEV}_{1}$, and radiograph score) were combined in a multivariate analysis to test the pool effect of sex and glucose intolerance, there was a significant interaction between the 2 factors. The female patients with glucose intolerance had poorer clinical score, 6-min walk distance, $\mathrm{FEV}_{1}$, and radiograph score than the male patients. There was no difference between the male and female subjects with normal glucose tolerance.

Fifty-nine patients $(67 \%)$ had normal glucose tolerance, $15(17 \%)$ had impaired glucose tolerance, and $14(16 \%)$ had CF-related diabetes ( 7 with fasting hyperglycemia, and 7 with hyperglycemia 2 hours after ingesting glucose). Glucose intolerance was strongly associated with pancreatic insufficiency. ${ }^{31,32}$

Milla et al $^{13}$ followed 152 patients with CF over 4 years and found a higher prevalence of impaired glucose tolerance than in our study. At baseline, $45 \%$ of their patients 

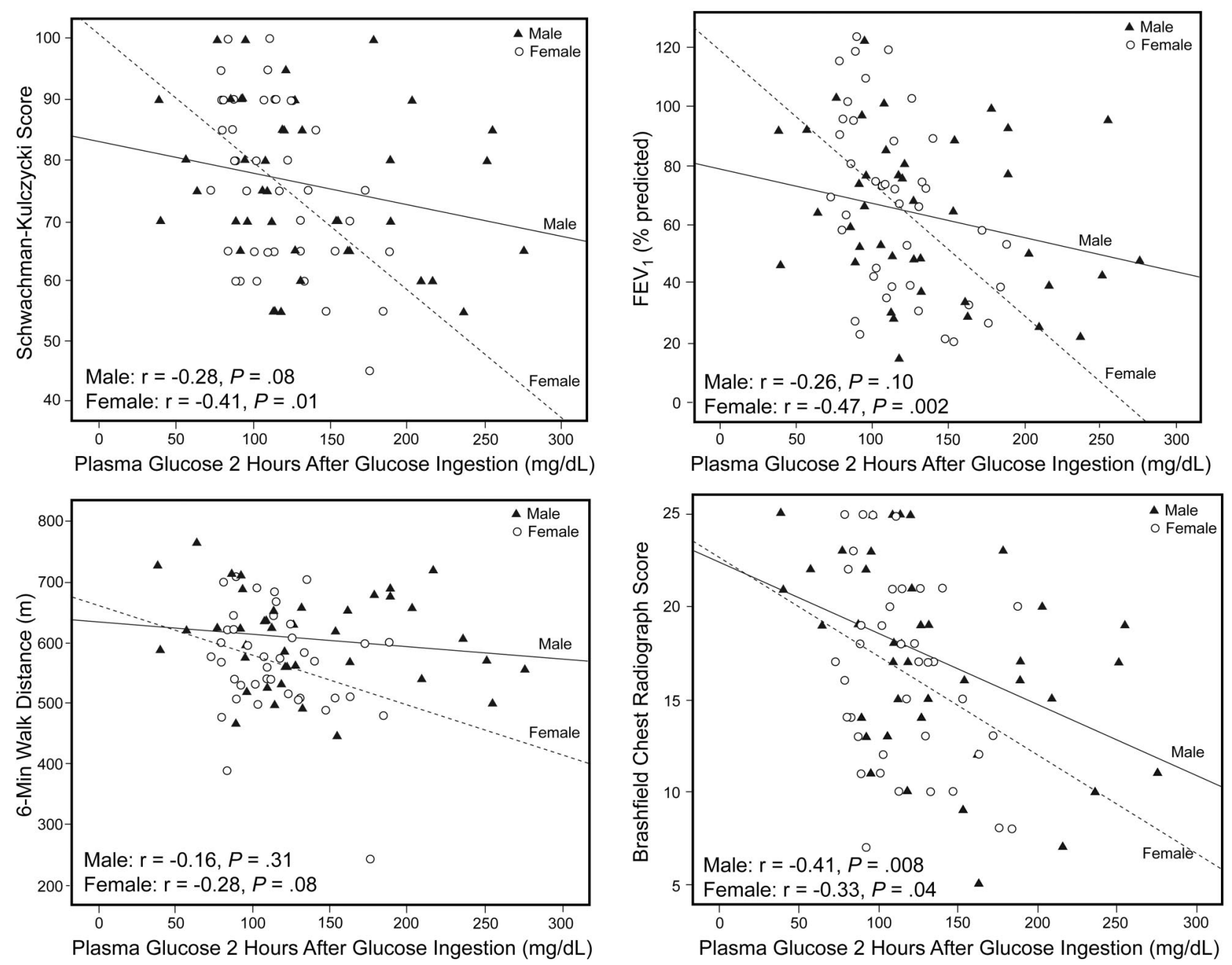

Fig. 2. Plasma glucose 2 hours after glucose ingestion versus sex, Schwachman-Kulczycki clinical score, FEV 1 , 6-min walk distance, and Brasfield chest radiograph score.

had normal glucose tolerance, $39 \%$ had impaired glucose tolerance, and $16 \%$ had CF-related diabetes. The rates of $\mathrm{FEV}_{1}$ and FVC decline correlated with the glucose-tolerance groups; the highest rates of decline were among the CF-related diabetes/no fasting hyperglycemia group. Adjustment for the potential confounding effect of sex did not cause any major modification in those trends.

Garagorri et al $^{32}$ studied 28 patients with $\mathrm{CF}$ to evaluate predisposing factors of impaired glucose tolerance. In contrast to our study, they found that glucose tolerance was not associated with lung function or clinical score. They reported no significant differences in sex or anthropometry between their glucose-tolerance groups.

Sims et al ${ }^{19}$ compared 323 patients with established CF-related diabetes to $489 \mathrm{CF}$ control subjects with normal glucose tolerance. Only female subjects with CF-related diabetes had significantly worse lung function than the sex-matched normal-glucose-tolerance control subjects.
That study did not evaluate subjects with impaired glucose tolerance.

Tofé et al ${ }^{33}$ evaluated insulin-secretion kinetics and insulin sensitivity in $50 \mathrm{CF}$ patients with normal glucose tolerance, impaired glucose tolerance, and $\mathrm{CF}$-related diabetes. CF patients with impaired glucose tolerance presented worse clinical status, under-nutrition, and impaired pulmonary function. Tofé et al did not evaluate sex-related differences in impaired glucose tolerance.

Costa et $\mathrm{al}^{1}$ studied $109 \mathrm{CF}$ patients over 18 years old to determine the association between glucose tolerance and CF clinical status. They found no significant differences between the groups for sex, age, weight, or BMI. They did find an association between glucose-tolerance abnormality and worse clinical status.

In the present study the 6-min walk distance was significantly less in the female patients than the male patients, but female patients tend to have shorter 6-min walk distances, not 


\section{Glucose Intolerance in Patients With Cystic Fibrosis}

specifically related to more severe lung disease, but due to less muscle mass. We attempted to overcome this bias by using percent-of-predicted 6-min walk distances, but we still observed the same result for female patients.

At-rest $\mathrm{S}_{\mathrm{pO}_{2}}$ was significantly lower in the impairedglucose-tolerance group than in the normal-glucose-tolerance group, and the $\mathrm{S}_{\mathrm{pO}_{2}}$ difference before versus after $6 \mathrm{MWT}$ was greater in the impaired-glucose-tolerance group.

One mechanism by which insulin deficiency might impact pulmonary function in CF patients is by adversely affecting nutrition by promoting a catabolic state. ${ }^{13}$ In the present study the 3 glucose-tolerance groups had no differences in BMI or nutritional classification. It is possible that the aggressive nutritional treatment interventions and enzyme replacement may maintain an adequate BMI in these patients. Similar to our findings, other studies found no significant differences between glucose tolerance and nutrition. ${ }^{1,13,34,35}$ In the pediatric and adult CF program at Hospital de Clínicas de Porto Alegre, patients are monitored by a nutritionist. The dietary management of CFrelated diabetes maintains a high-energy-content diet and patients are advised not to limit their intake of carbohydrates, high-fat foods, or proteins. ${ }^{11}$

It was surprising that our impaired-glucose-tolerance patients performed worse than the established CF-relateddiabetes patients. We speculate that the CF-related-diabetes patients may maintain tighter metabolic control than the impaired-glucose-tolerance patients. Also, the impaired-glucose-tolerance patients may be undiagnosed for long periods before aggressive metabolic control is achieved, which may explain their deterioration, because clinicians wait for overt CF-related diabetes before aggressively intervening.

Another concerning finding was the lack of difference in age among our glucose-tolerance groups. We would expect that older individuals are more likely to develop glucose-tolerance impairment. However, the low average age $(20 \pm 7 \mathrm{y})$ of the CF subjects in the study might explain this finding.

\section{Limitations}

The cross-sectional study design does not provide enough evidence to define the temporal relationship between glucose intolerance/CF-related diabetes and health decline or lung-function decline in $\mathrm{CF}$ patients. Also, there was a low prevalence of $\mathrm{CF}$-related diabetes in the population we studied. For the statistical analysis we included the patients with fasting CF-related diabetes and the patients with no fasting hyperglycemia in the same group. Furthermore, the large number of patients with pancreatic sufficiency in the normal-glucose-tolerance group may confound the poor results in the impaired-glucose-tolerance and CF-related-diabetes groups. The female patients also tended to be older than the male patients, although that difference was not statistically significant. However, our MANOVA analysis found similar results between the sexes, with age as the covariate.

\section{Conclusions}

Glucose-tolerance impairment was related to poor clinical score, lower at-rest $\mathrm{S}_{\mathrm{pO}_{2}}$, greater $\mathrm{S}_{\mathrm{pO}_{2}}$ difference before versus after $6 \mathrm{MWT}$, poor lung function, and lower radiograph score in patients with $\mathrm{CF}$. Combining clinical score, 6-min walk distance, $\mathrm{FEV}_{1}$, and radiograph score in a multivariate analysis, the overall effect indicated poorer performance in those variables in the female patients with glucose intolerance than in the male patients.

\section{ACKNOWLEDGMENTS}

We thank Daniela Benzano MSc and Vânia Naomi Hirakata MSc, Statistics Department, Hospital de Clínicas de Porto Alegre, for their support in the statistical analyses.

\section{REFERENCES}

1. Costa M, Potvin S, Hammana I, Malet A, Berthiaume Y, Jeanneret A, et al. Increased glucose excursion in cystic fibrosis and its association with a worse clinical status. J Cyst Fibros 2007;6(6):376-383.

2. Lombardo F, De Luca F, Rosano M, Sferlazzas C, Lucanto C, Arrigo $\mathrm{T}$, et al. Natural history of glucose tolerance, beta-cell function and peripheral insulin sensitivity in cystic fibrosis patients with fasting euglycemia. Eur J Endocrinol 2003;149:53-59.

3. Marshall BC, Butler SM, Stoddard M, Moran AM, Liou TG, Morgan WJ. Epidemiology of cystic fibrosis-related diabetes. J Pediatr 2005; 146(5):681-687.

4. Moran A, Hardin D, Rodman D, Allen HF, Beall RJ, Borowitz D, et al. Diagnosis, screening and management of cystic fibrosis related diabetes mellitus: a consensus conference report. Diabetes Res Clin Pract 1999;45(1):61-73.

5. Koch C, Rainisio M, Madessani U, Harms HK, Hodson ME, Mastella G, et al. Presence of cystic fibrosis-related diabetes mellitus is tightly linked to poor lung function in patients with cystic fibrosis: data from the European epidemiologic registry of cystic fibrosis. Pediatr Pulmonol 2001;32(5):343-350.

6. Lanng S, Hansen A, Thorsteinsson B, Nerup J, Koch C. Glucose tolerance in patients with cystic fibrosis: five year prospective study. BMJ 1995;311(7006):655-659.

7. Lands LC, Heigenhauser GJ, Jones NL. Analysis of factors limiting maximal exercise performance in cystic fibrosis. Clin Sci (Lond) 1992;83(4):391-397.

8. Shah AR, Gozal D, Keens TG. Determinants of aerobic and anaerobic exercise performance in cystic fibrosis. Am J Respir Crit Care Med 1998;157(4 Pt 1):1145-1150.

9. Ziegler B, Rovedder PM, Oliveira CL, Schuh SJ, Silva FA, Dalcin Pde T. Predictors of oxygen desaturation during the six-minute walk test in patients with cystic fibrosis. J Bras Pneumol 2009;35(10): 957-965.

10. American Thoracic Society. ATS statement: guidelines for the sixminute walk test. Am J Respir Crit Care Med 2002;166(1):111-117.

11. Brennan AL, Geddes DM, Gyi KM, Baker EH. Clinical importance of cystic fibrosis-related diabetes. J Cyst Fibros 2004;3(4):209-222. 


\section{Glucose Intolerance in Patients With Cystic Fibrosis}

12. Finkelstein SM, Wielinski CL, Elliott GR, Warwick WJ, Barbosa J, Wu SC, Klein DJ. Diabetes mellitus associated with cystic fibrosis. J Pediatr 1988;112(3):373-377.

13. Milla CE, Warwick WJ, Moran A. Trends in pulmonary function in patients with cystic fibrosis correlate with the degree of glucose intolerance at baseline. Am J Respir Crit Care Med 2000;162(3 Pt 1):891-895

14. Rolon MA, Benali K, Munck A, Navarro J, Clement A, TubianaRufi N, et al. Cystic fibrosis-related diabetes mellitus: clinical impact of prediabetes and effects of insulin therapy. Acta Paediatr 2001; 90(8):860-867.

15. Rosenecker J, Eichler I, Bärmeier H, von der Hardt H. Diabetes mellitus and cystic fibrosis: comparison of clinical parameters in patients treated with insulin versus oral glucose-lowering agents. Pediatr Pulmonol 2001;32(5):351-355.

16. Demko CA, Byard PJ, Davis PB. Gender differences in cystic fibrosis: Pseudomonas aeruginosa infection. J Clin Epidemiol 1995;48(8): 1041-1049.

17. Aurora P, Wade A, Whitmore P, Whitehead B. A model for predicting life expectancy of children with cystic fibrosis. Eur Respir J 2000;16(6):1056-1060.

18. Allen JR, McCauley JC, Selby AM, Waters DL, Gruca MA, Baur LA, et al. Differences in resting energy expenditure between male and female children with cystic fibrosis. J Pediatr 2003;142(1):15-19.

19. Sims EJ, Green MW, Mehta A. Decreased lung function in female but not male subjects with established cystic fibrosis-related diabetes. Diabetes Care 2005;28(7):1581-1587.

20. Milla CE, Billings J, Moran A. Diabetes is associated with dramatically decreased survival in female but not male subjects with cystic fibrosis. Diabetes Care 2005;28(9):2141-2144.

21. Rosenstein BJ, Cutting GR; Cystic Fibrosis Foundation Consensus Panel. The diagnosis of cystic fibrosis: a consensus statement. J Pediatr 1998;132(4):589-595.

22. Shwachman H, Kulczycki LL. Long-term study of one hundred five patients with cystic fibrosis; studies made over a five- to fourteenyear period. AMA J Dis Child 1958;96(1):6-15.

23. Borowitz D, Baker RD, Stallings V. Consensus report on nutrition for pediatric patients with cystic fibrosis. J Pediatr Gastroenterol Nutr 2002;35(3):246-259.
24. Sinaasappel M, Stern M, Littlewood J, Wolfe S, Steinkamp G, Heijerman HG, et al. Nutrition in patients with cystic fibrosis: a European Consensus. J Cyst Fibros 2002;1(2):51-75.

25. Miller MR, Hankinson J, Brusasco V, Burgos F, Casaburi R, Coates A, et al; ATS/ERS Task Force. Standardisation of spirometry. Eur Respir J 2005;26(2):319-338.

26. Brasfield D, Hicks G, Soong S, Tiller RE. The chest roentgenogram in cystic fibrosis: a new scoring system. Pediatrics 1979;63(1): 24-29.

27. American Diabetes Association. Diagnosis and classification of diabetes mellitus. Diabetes Care 2007;30(Suppl 1):S42-S47.

28. Enright PL, Sherrill DL. Reference equations for the six-minute walk in healthy adults. Am J Respir Crit Care Med 1998;158(5 Pt 1): 1384-1387.

29. Li AM, Yin J, Au JT, So HK, Tsang T, Wong E, et al. Standard reference for the six-minute-walk test in healthy children aged 7 to 16 years. Am J Respir Crit Care Med 2007;176(2):174-180.

30. Sheehan-Holt JK. MANOVA simultaneous test procedures: the power and robustness of restricted multivariate contrasts. Educ Phychol Meas 1998;58:861-881.

31. Choo-Kang LR, Zeitlin PL. Type I, II, III, IV, and V cystic fibrosis transmembrane conductance regulator defects and opportunities for therapy Curr Opin Pulm Med 2000;6(6):521-529.

32. Garagorri JM, Rodríguez G, Ros L, Sánchez A. Early detection of impaired glucose tolerance in patients with cystic fibrosis and predisposition factors. J Pediatr Endocrinol Metab 2001;14(1):5360.

33. Tofé S, Moreno J, Máiz L, Alonso M, Escobar H, Barrio R. Insulinsecretion abnormalities and clinical deterioration related to impaired glucose tolerance in cystic fibrosis. Eur J Endocrinol 2005;152(2): 241-247.

34. Elder DA, Wooldridge JL, Dolan LM, D'Alessio DA. Glucose tolerance, insulin secretion, and insulin sensitivity in children and adolescents with cystic fibrosis and no prior history of diabetes. J Pediatr 2007;151(6):653-658

35. Solomon MP, Wilson DC, Corey M, Kalnins D, Zielenski J, Tsui LC, et al. Glucose intolerance in children with cystic fibrosis. J Pediatr 2003;142(2):128-132.

This article is approved for Continuing Respiratory Care Education credit. For information and to obtain your CRCE

(free to AARC members) visit

RCJournal.com

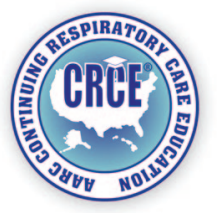

